only be possible because they are working during embryogenesis, a kind of timewarped space where the relative position of signaling centers and responding cells change as a function of developmental time. These findings strongly resemble limb morphogenesis, in which a complex timedependent integration of BMP, RA, Shh and FGF signaling within rostral-caudal, dorsalventral and proximal-distal axes create distinct Hox protein patterns that specify bone and digit identity.

The new data also raise intriguing new questions such as how exactly RA-mediated de-repression works. The dissociation of CT and LMC columns is only the beginning of a dissection of several different motor columns and subdivisions of motor columns that have overlapping yet distinct locations along the extent of the spinal cord. Still, the recent work has added a new dimension to the work on motor neuron development, by showing that the principles of homeodomain protein function along the dorsalventral axis and rostral-caudal axis are similar-a graded activity of a signaling factor establishes homeodomain boundaries, which are further refined by selective crossrepression among the homeodomain transcription factors. The convergence of these two programs then ensures correct motor neuron specification along the dorsal-ventral and rostral-caudal axes.

1. Tosney, K.W., Hotary, K.B. \& Lance-Jones, C. Bioessays 17, 379-382 (1995).

2. Dasen, J., Liu, J.-P. \& Jessell, T. Nature 425 , 926-933 (2003).

3. Novitch, B.G., Wichterle, H., Jessell, T.M. \& Sockanathan, S. Neuron 40, 81-95 (2003)

4. Diez del Corral, R. et al. Neuron 40, 65-79 (2003).

5. Ensini, M., Tsuchida, T.N., Belting, H.G. \& Jessell, T.M. Development 125, 969-982 (1998).

6. Liu, J.P., Laufer, E. \& Jessell, T.M. Neuron 32, 997-1012 (2001).

7. Bel-Vialar, S., Itasaki, N. \& Krumlauf, R. Development 129, 5103-5115 (2002).

8. Jessell, T. M. Nat. Rev. Genet. 1, 20-29 (2000).

9. Sockanathan, S., Perlmann, T. \& Jessell, T.M. Neuron 40, 97-111 (2003).

\title{
Folding the cortex
}

The cortical surface of a normal mouse is smooth (top). The cortices of primates, including humans, are folded up into a complex landscape of gyri and sulci. In this issue (page 1292), Kingsbury et al. report that treating cultured cortical hemispheres from mouse embryos with lysophosphatidic acid (LPA) for only 17 hours caused them to expand and fold up into a structure that resembles a primate brain (bottom; blue is DAPI staining).

The folded cortices were thicker and contained more cells than controls: both more differentiated neurons in the cortical plate and more neural progenitor cells in the ventricular zone. LPA induced terminal mitosis-the generation of neurons from progenitors-and it also reduced apoptotic death of progenitor cells. Although LPA can induce cell proliferation in other systems, Kingsbury et al. saw no increase in S-phase cells, so most of the increase in cell number seemed to be due to inhibition of cell death. The effects of LPA were mediated by one or both of the closely related $\mathrm{G}$ protein-coupled receptors $\mathrm{LPA}_{1}$ and $\mathrm{LPA}_{2}$, as cortices from mouse embryos lacking these two receptors did not fold up after LPA treatment.

Neurons in the brain produce LPA, which can activate a number of intracellular signaling pathways. Despite the presence of the LPA signal, however, mice lacking $\mathrm{LPA}_{1}, \mathrm{LPA}_{2}$ or both receptors show no evident cortex malformation, suggesting that such signals are not important for the development of the smooth cortex of the mouse. On the other hand, the ability of excess LPA to induce cortical folding in mice suggests the intriguing possibility that LPA might contribute to cortical development in primates.

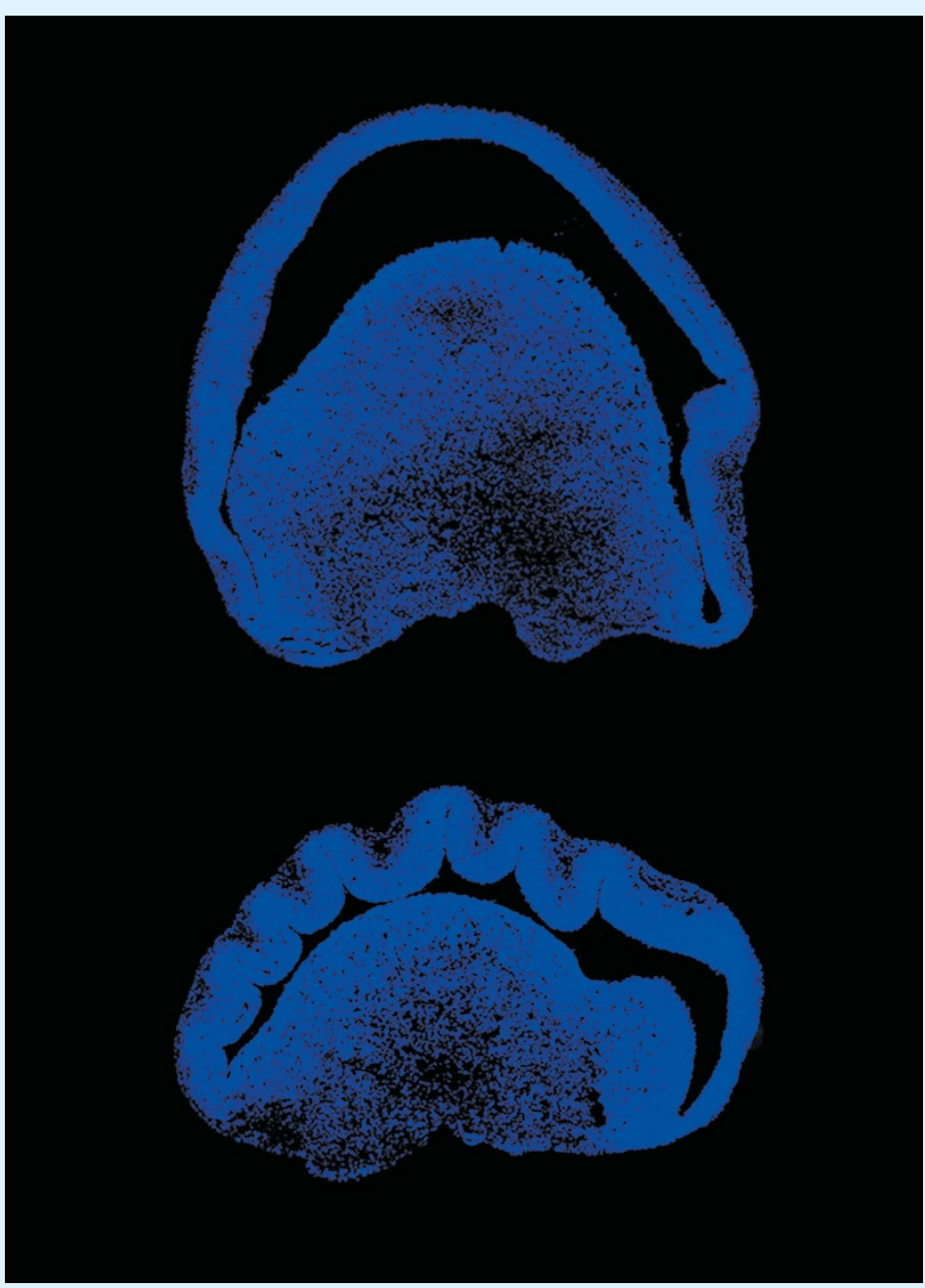

\section{Annette Markus}

